\title{
PANI/MWCNT based humidity sensor
}

\author{
Hammad R. Humud ${ }^{1}$, Jassim M. Najem ${ }^{2}$, Qudama Khames ${ }^{2}$ \\ ${ }^{1}$ Department of Physics, College of Science, University of Baghdad, Baghdad, Iraq \\ ${ }^{2}$ Department of Physics, College of Science, University of Anbar, Iraq \\ E-mail: dr.hammad6000@yahoo.com
}

\begin{abstract}
Polyaniline Multi wall Carbon nanotube (PANI/MWCNTs) nanocomposite thin films have been prepared by Plasma jet polymerization at low frequency on glass substrate with preliminary deposited aluminum electrodes to form Al/PANI-MWCNT/Al surface-type capacitive humidity sensors, the gap between the electrodes about $50 \mu \mathrm{m}$ and the MWCNTs weight concentration varied between $0,1,2,3,4 \%$. The diameter of the MWCNTs was in the range of $8-15 \mathrm{~nm}$ and the length $10-55 \mu \mathrm{m}$. The capacitancehumidity relationships of the sensors were investigated at humidity levels from 35 to $90 \% \mathrm{RH}$. The electrical properties showed that the capacity increased with increasing relative humidity, and that the sensitivity of the sensor increases with the increase of the additive (MWCNTs); while each of the response time and the recovery time increasing with concentration. The change in MWCNTs concentration leads to a change in the energy gap as well as the initial capacity. The capacitance increases linearly with the relative humidity at MWCNTs concentration of $3 \%$ for thus the possibility of manufacturing humidity sensor with good specifications at this concentration.
\end{abstract}

Key words

Carbon nanotubes, Humidity sensor, Capacitance-type humidity sensor.

Article info.

Received: Dec. 2016

Accepted: Jan. 2017

Published: Jun. 2017

$$
\begin{aligned}
& \text { متحسس رطوبة بالاستناد الى بولي أنيلين - انابيب الكاربون النانوية متعددة الجدران } \\
& \text { حمد رحيم حمود1، جاسم محمد نجم²، قدامة خميس حماد² }
\end{aligned}
$$

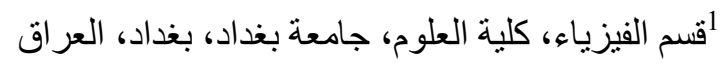

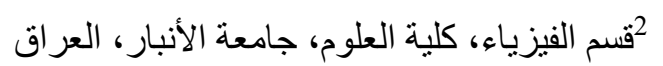

حضرت متراكبات الاغشية النانوية بولي أنيلين-انابيب الكاربون النانوية متعددة الجدران

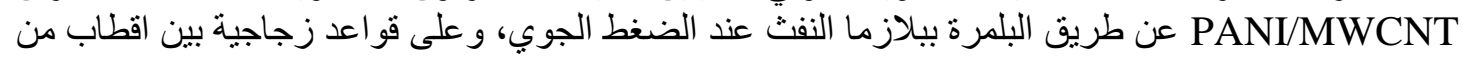

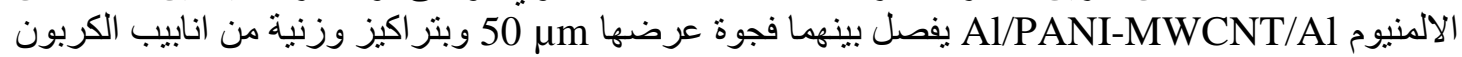

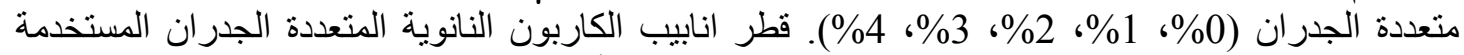

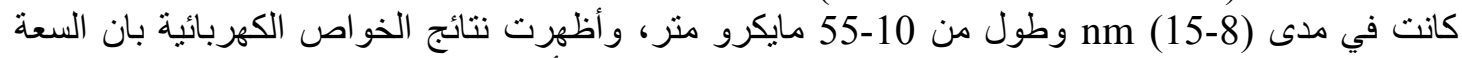

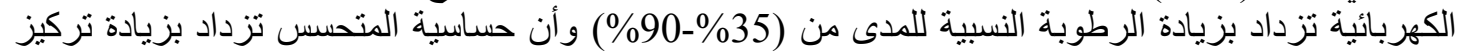

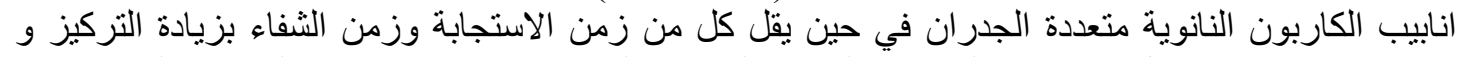

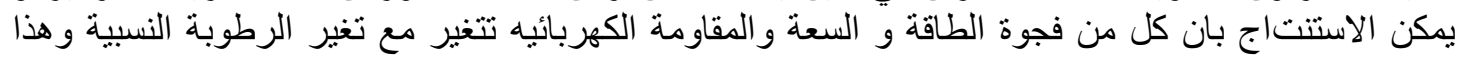

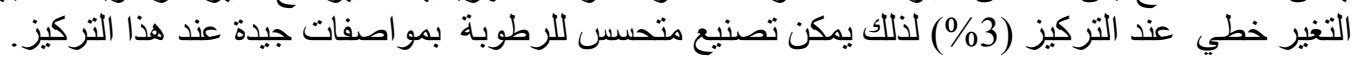




\section{Introduction}

Carbon nanotubes (CNTs) have attracted considerable attention since their discovery by Iijima in 1991[1]. There was great interest in exploring and exploiting their unique characteristics for various applications [2,3]. CNTs have been attracted significant interest owing to their application in fabricating new categories of advanced materials in result of their unique structural, mechanical and electronic properties [4]. The polymeric composite materials filled with carbon nanotubes (CNT) attract great attention [5]. These materials demonstrate excellent physical properties and functional characteristics. In particular, introduction of a very small quantity of CNT in a polymeric material may significantly affect its electrical conductivity, mechanical properties, and thermal stability [6]. The polyaniline (PANI) is one of the most interesting polymers due to its good stability, easy preparation and its potential for fabrication of different microelectronic devices $[7,8]$.

The humidity sensors play important role for measurement and controlling of humidity in many industrials and medical fields such as food storage, medicine stores, hospitals، electronic devices, computer rooms and all kind of machines. In recent years, the fabrication and study of electric, electronic and photonic devices employing organic semiconductors have attracted much attention [9,10]. Humidity can be determined by methods and devices such as psychrometric (wet- and drybulb hydrometers), mechanical hygrometers (exploiting the change in dimensions of porous materials such as paper and hair), dew point sensors, electrolytic sensor, spectroscopic sensors and hygrometers where capacity or resistance are measured.
The last method is one of the most suitable from practical point of view because the electric sensors may have small sizes, short response and recovery times, high reliability, the possibility to use them in telemetry systems and low costs. Humidity sensors are widely used in semiconductor, automobile, medical, pharmaceutical, health caring, textile, paper, agriculture and food industry $[11,12]$. Measurement and control of humidity is very important not only for human comfort but also for manufacturing processes and industrial products [13] because of universal existence of water, which affects the human health and physical properties of materials [14].

The adsorption and absorption of water vapor may result in many different physical phenomena. It has influence on the dielectric properties of certain materials which is, for example the principle of operation in case of capacitive humidity sensors. The electric (DC) conduction may be altered due to a change in ionic conduction. The adsorption of water on semiconductor surfaces may alter the band-bending (barrier effect) altering both AC and DC conductance [15]. Humidity refers to the water vapor content in air or other gases. It is one of the most frequently measured physical quantities. Humidity measurements can be stated in a variety of terms and units. The three commonly used terms are absolute humidity, dew/frost point and relative humidity (RH). Absolute humidity is the ratio of the mass of water vapor to the volume of air or gas in which the water vapor resides. It is commonly expressed in grams per cubic meter. Dew point is the temperature (above $0{ }^{\circ} \mathrm{C}$ ) at which the water vapor in a gas condenses to form liquid water. Frost point is the temperature (below $0{ }^{\circ} \mathrm{C}$ ) at which the vapor condenses to ice. 
Dew/Frost point is expressed in ${ }^{\circ} \mathrm{C}$ or ${ }^{\circ} \mathrm{F}$ and is a function of the pressure of the gas but is independent of temperature; therefore it provides a better absolute measurement of water vapor content. The ratio of the percentage of water vapor present in air at a particular temperature and pressure to the maximum amount of water vapor the air can hold at that temperature and pressure is called relative humidity $(R H)$. It is often expressed as a percentage using the following expression, as Eq.(1) where $P \mathrm{~V}$ is the partial pressure of the water vapor and $P \mathrm{~S}$ is the saturation water vapor pressure. $\mathrm{RH}$ is a function of temperature, and thus it is a relative measurement. Most of the humidity sensors available on the market are $\mathrm{RH}$ sensors $[16,17]$.

$\mathrm{RH}=\mathrm{P}_{\mathrm{v}} / \mathrm{P}_{\mathrm{s}} \times 100 \%$

In this work, the fabrication and investigation of Al/PANI-MWCNT/Al surface-type capacitive humidity sensors of different concentration of MWCNT is undertaken and effect of humidity on the capacitance is examined.

\section{Experimental}

MWCNT purity $95 \%$ was supplied by neutrino factory, India. The diameter of the MWCNT was in the range of $8-15 \mathrm{~nm}$ and the length 10-50 $\mu \mathrm{m}$. PANI / MWCNTS have been prepared by aerosol assisted plasma polymerization. Thin films were prepared by dielectric barrier discharge plasma jet. The thin films were deposited on glass substrates. PANI / MWCNTS nanocomposite thin films were prepared with different MWCNTS weight concentration $1 \%$, $2 \%, 3 \%$, and $4 \%$. Argon gas with flow rate of $1 \mathrm{l} / \mathrm{min}$ passes through the nebulizer which contains a mixture of MWCNTs and aniline. Fig.1 shows schematic diagram for PANI/MWCNTs nanocomposites thin films preparation by non-equilibrium atmospheric pressure plasma jet. The film deposition was carried out for 50 min under constant carrier gas flow rate and the substrate at room temperature. The substrate moved on the $\mathrm{x}$ and $\mathrm{y}$ direction mechanically for the purpose of obtaining a homogeneous films thickness along the substrate area. Aluminum electrodes were deposited by vacuum evaporation technique on thoroughly cleaned glass substrate. The gap between electrodes and length of the gap was equal to 50 $\mu \mathrm{m}$. The sensor in Fig. 2 consists of a pair of $\mathrm{Al}$ interdigital electrodes and PANI/MWCNTs film coated on the Al electrodes. The surface type capacitive sensor, Al/PANIMWCNT/Al was fabricated. Cross-sectional view of the fabricated capacitive sensor is shown in Fig.2. Measurement of the capacitance was done by conventional instruments LCR-meter type (GWINSTEK-821) at the frequency of $1 \mathrm{kHz}$, the capacitance was measured, at room temperature with rang of $\mathrm{RH}$ humidity (35-95). 


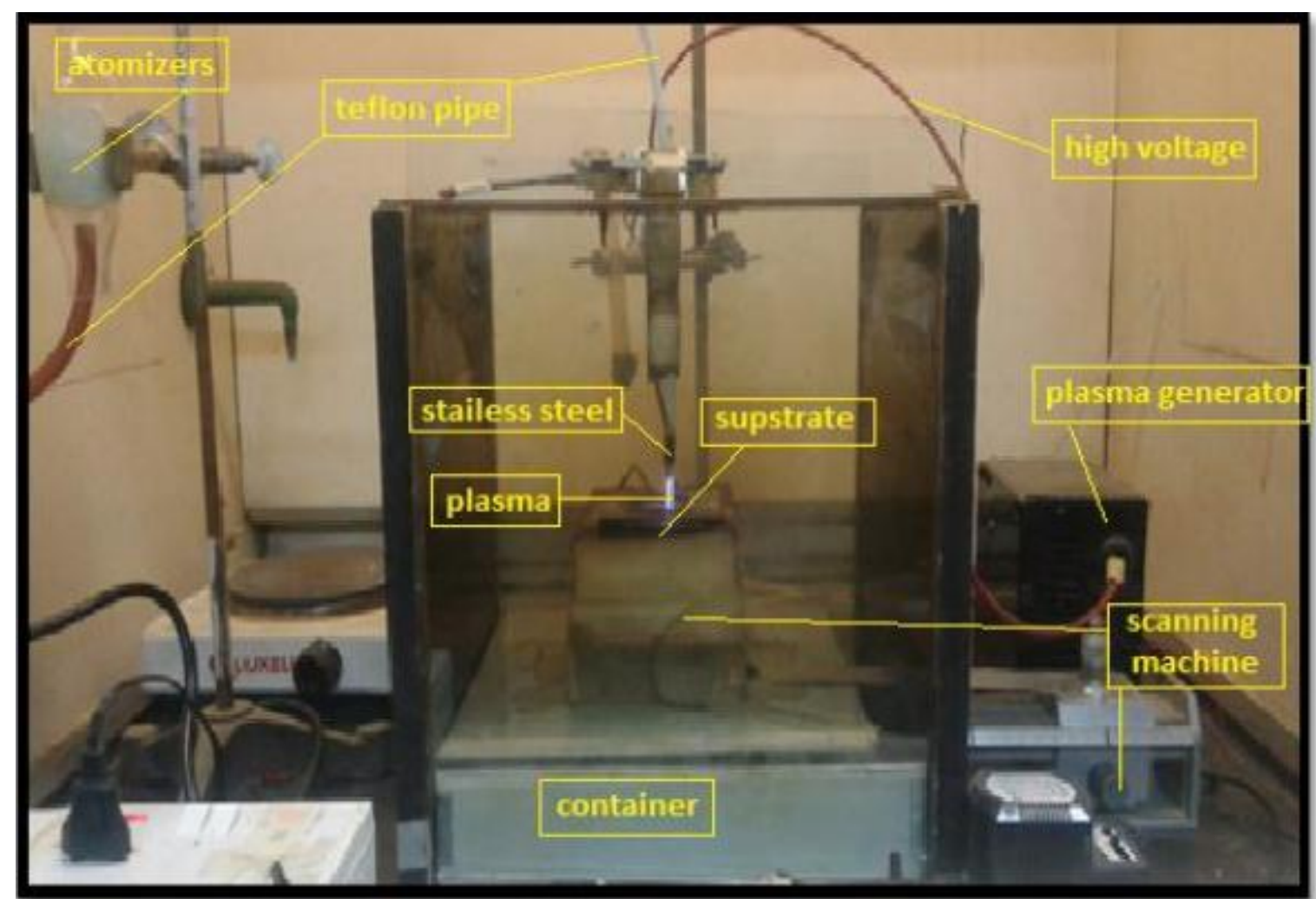

Fig.1: Schematic diagram for PANI/MWCNTs nanocomposites thin films preparation by non-equilibrium atmospheric pressure plasma jet.

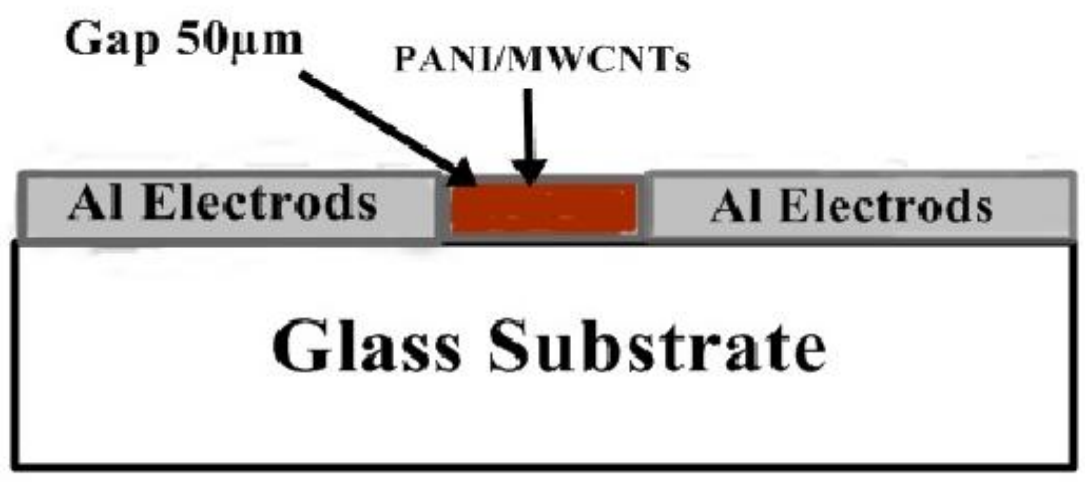

Fig.2: Schematic diagram of the sensor.

Results and discussion

A. Capacitance - humidity relationship

In order to determine the sensor capacitance dependence on the PANIIMWCNT concentration, five sensors were fabricated with MWCNT concentrations of $0 \mathrm{wt} \%, 1 \mathrm{wt} \%, 2 \mathrm{wt} \%$, $3 \mathrm{wt} \%$ and $4 \mathrm{wt} \%$. The measured capacitance-humidity relationships of Al/PANI-MWCNT /Al surface type humidity sensor are shown in Figs.3-7. The capacitance of the pristine PANI sensor was about $40 \mathrm{Pf}$. The sharp increase in capacitance was observed between $1 \mathrm{wt} \%$ and $4 \mathrm{wt} \%$, MWCNT concentrations, where the capacitance changed from $1022 \mathrm{pF}$ for $1 \mathrm{wt} \%$ to $4713 \mathrm{pF}$ for $4 \mathrm{wt} \%$. This behavior has been attributed to the occurrence of a percolation transition $[18,19]$. It is observed that the capacitance increase nearly linearly with the humidity for all MWCNT concentrations and become linearly with $3 \mathrm{wt} \%$ MWCNT concentration. 
The increase in capacitance with an increase in humidity can be explained by the following way. Firstly, dielectric constant for the MWCNT increases due to absorption of water molecules. Secondly, capacitance increases due to doping of the MWCNT by the water molecules, this doping increase the polarizability and the charges concentration, this leads to extra charge carriers.

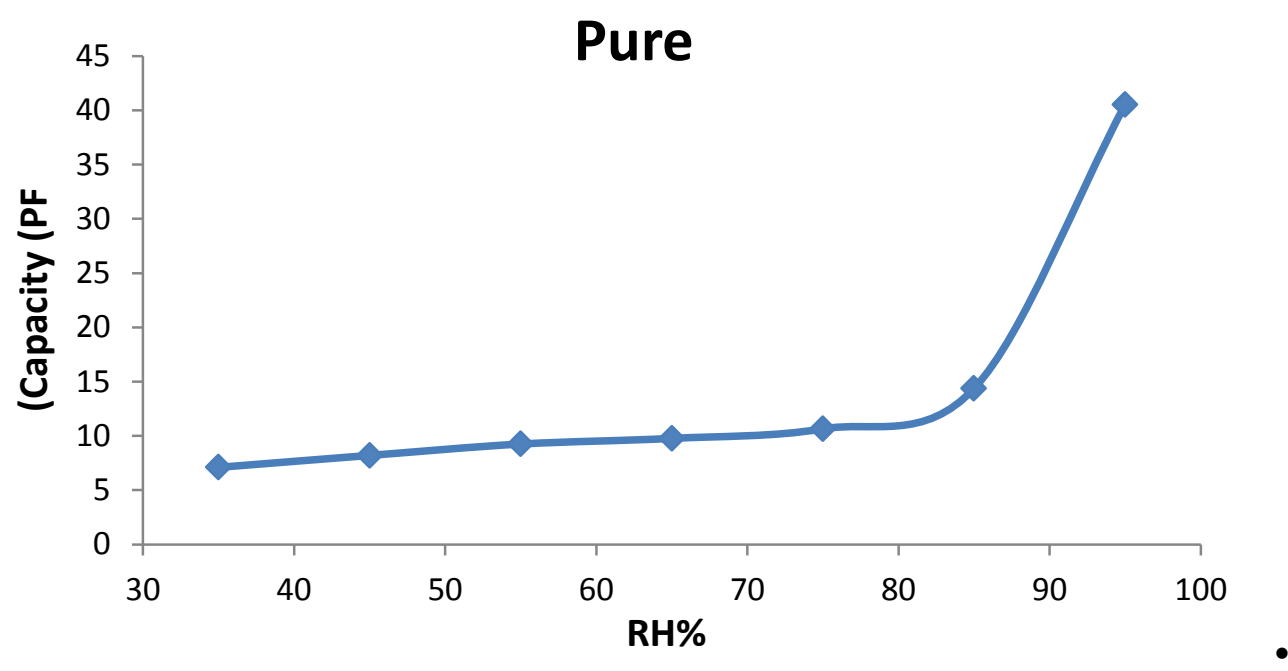

Fig.3: Humidity capacitance relationship for PANI humidity sensors.

\section{$1 \%$ CNT}

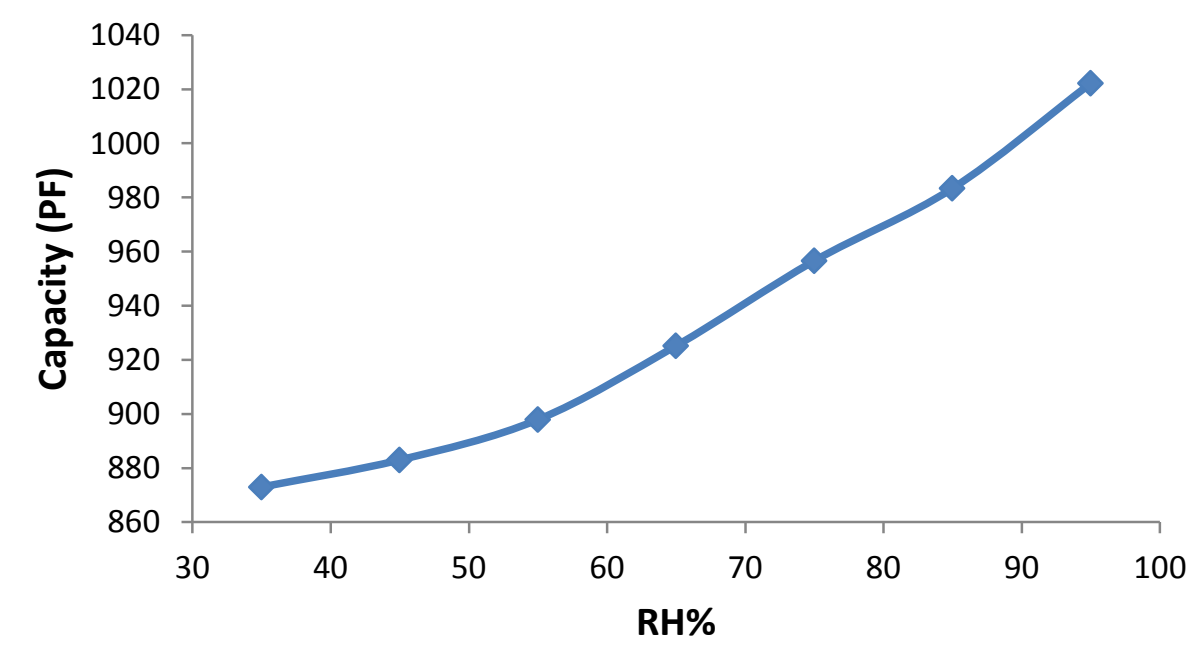

Fig.4: Humidity capacitance relationship for humidity sensors with $1 \%$ MWCNT. 


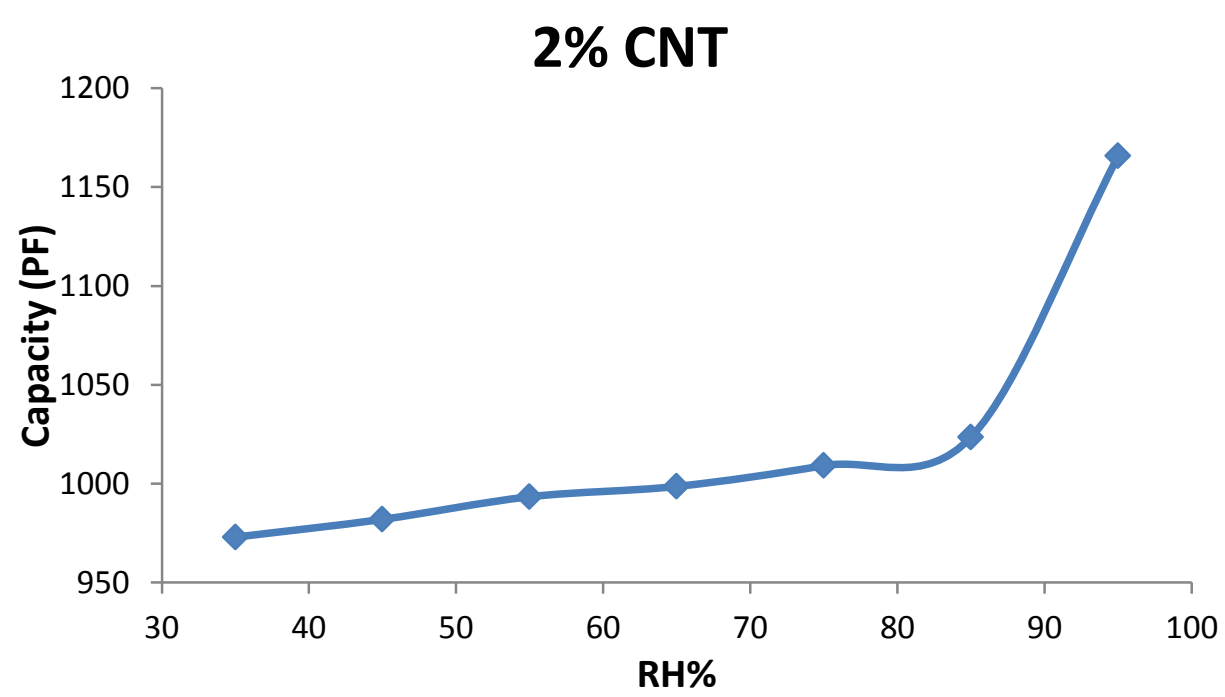

Fig.5: Humidity capacitance relationship for humidity sensors $2 \%$ MWCNT.

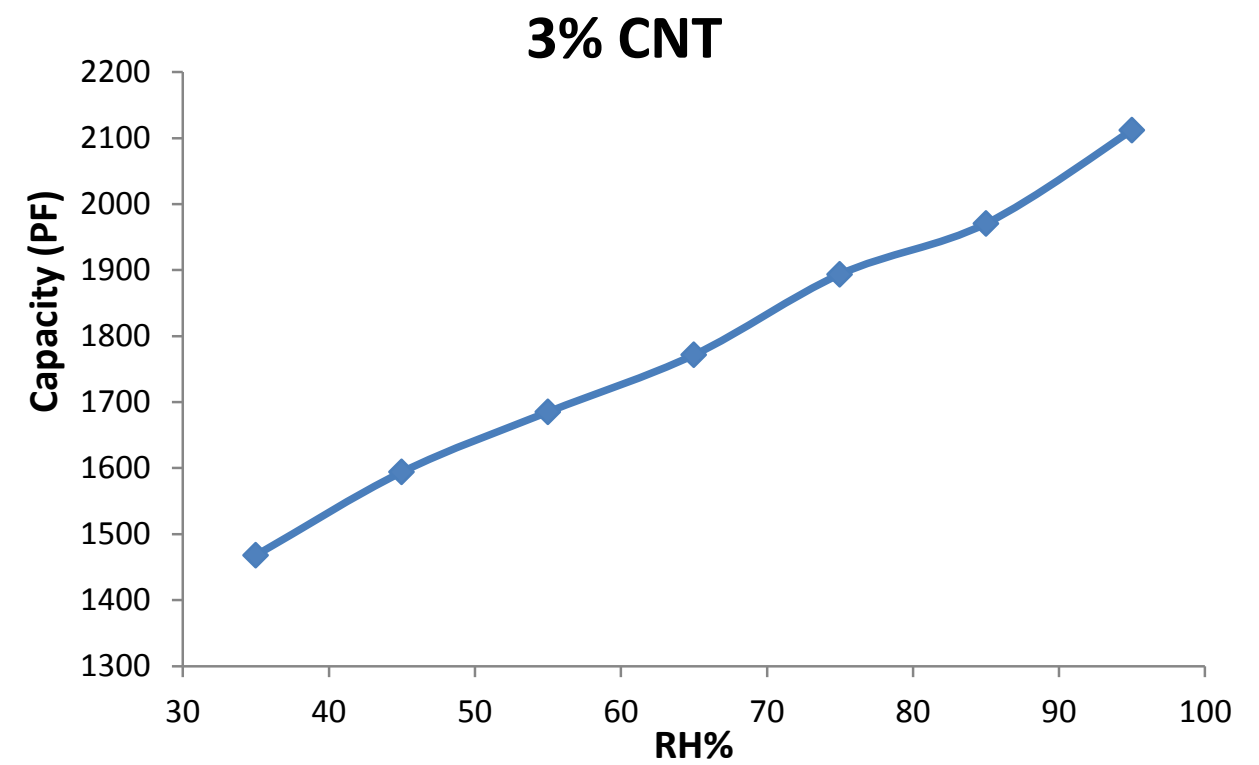

Fig.6: Humidity capacitance relationship for humidity sensors with 3\% MWCNT.

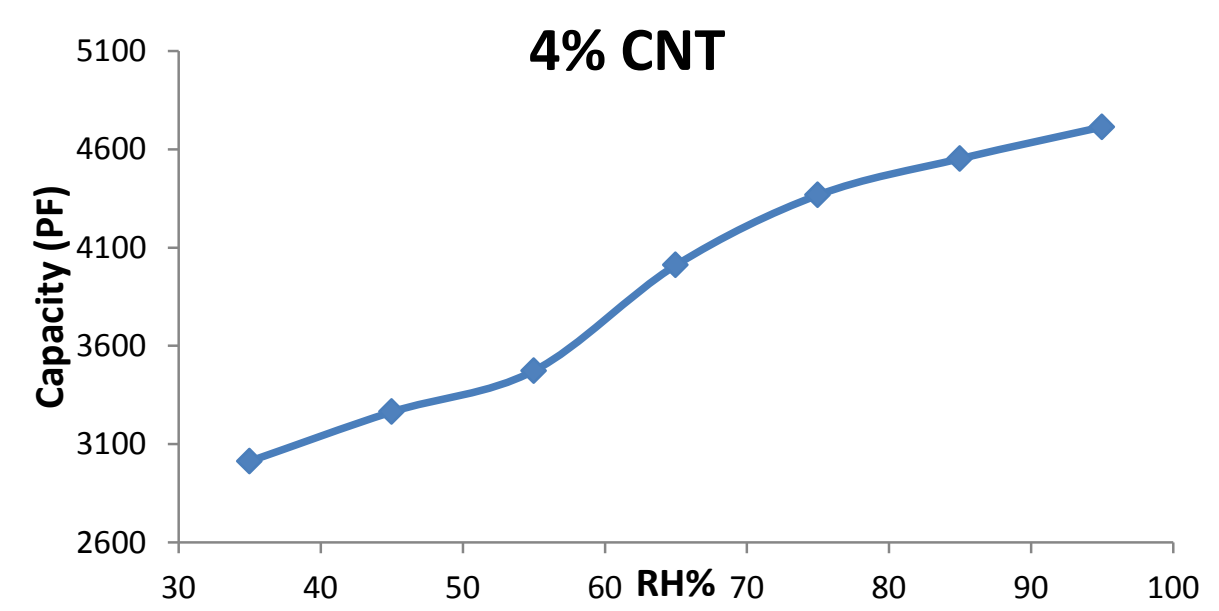

Fig.7: Humidity capacitance relationship for humidity sensors with 4\% MWCNT. 


\section{B. Sensor sensitivity}

The sensors sensitivity as a function of MWCNT concentration in the range of relativity humidity of $35-95 \%$, were shown in Fig.8. The Sensor Sensitivity(S) was calculated on the basis of the relationship following

$$
S=\frac{C 95 x \%-C 35 \%}{95 \% R H-35 \% R H}
$$

where $\mathrm{C} 95 \%$ and $\mathrm{C} 35 \%$ represent the capacitance of the sensors measured at $\mathrm{RH}=95 \%$ and $\mathrm{RH}=35 \%$, respectively. It is observed that the sensor sensitivity increase with the increase of MWCNT concentrations, the sensor sensitivity of the pristine PANI sensor was about (0.55 PF/RH \%) while it is become (28.3 PF/RH \%) at $4 \mathrm{wt} \%$ of MWCNT concentration.

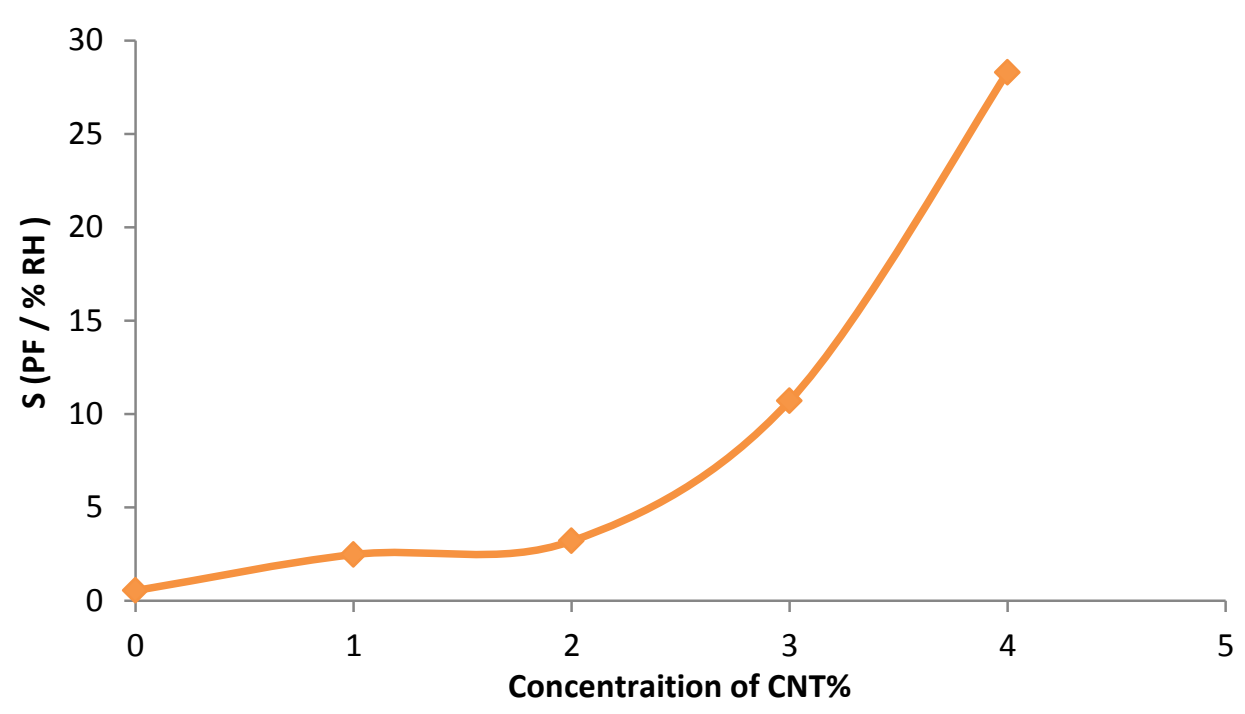

Fig.8: Sensors sensitivity as a function of MWCNT concentration.

\section{Response and recovery time}

The response and recovery behavior, corresponding to the water molecule adsorption and desorption process, is an important characteristic for evaluating the performance of humidity sensors. The response and recovery time of the sensor can be measured experimentally, in this work the humidity has been changed between $35 \% \mathrm{RH}$ and $95 \% \mathrm{RH}$. The response time of the sensor to humidity is reflected the sensor quality. The response time is defined as the time that took by the sensor as the output changes from the initial value to $90 \%$ of the final value when the RH springs from one value to another.

The response time and the recovery, according to the process of adsorption and desorption for humidity sensor with different MWCNT concentration shown in Figs. 9-14. It can see that the time of the adsorption process is longer than that of the desorption process, for all MWCNT concentration, which means that capillary condensation will spend more time than evaporation of the water. Table 1 shows the response time and the recovery time for PANI/ MWCNT nanocomposite with different MWCNT concentration. 


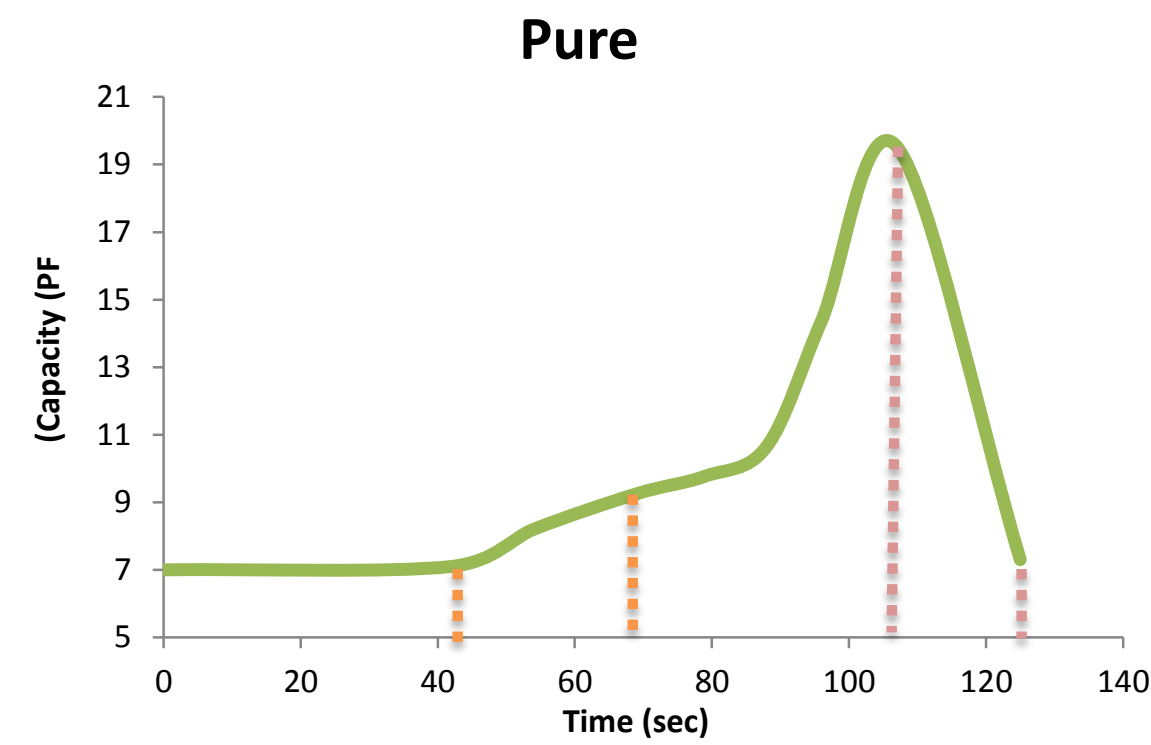

Fig.9: Response time and recovery time for PANI humidity sensor.

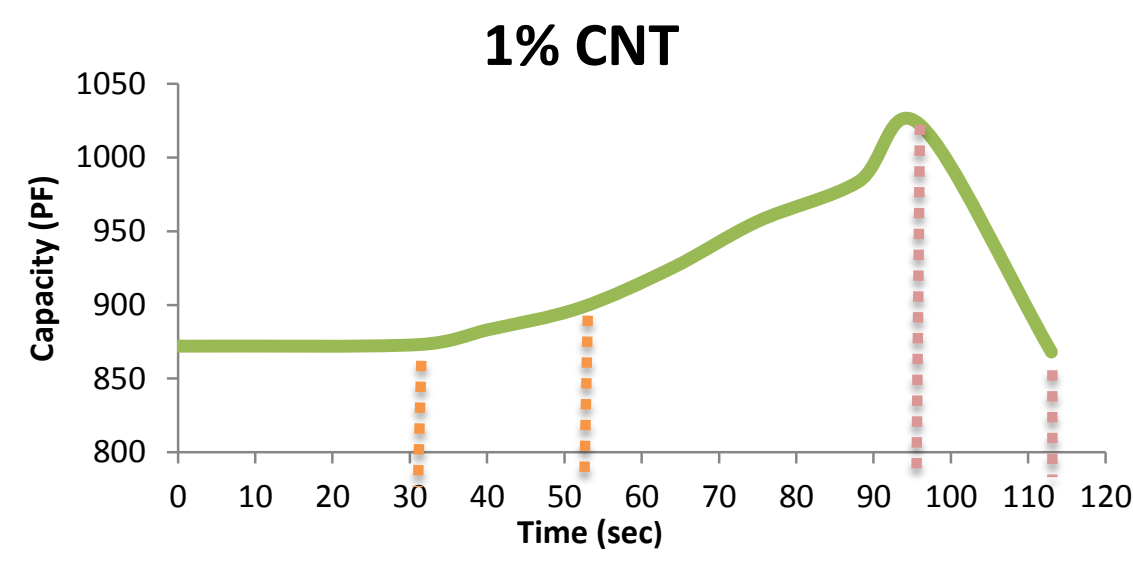

Fig.10: Response time and recovery time for humidity sensor with $1 w t \%$ MWCNT.

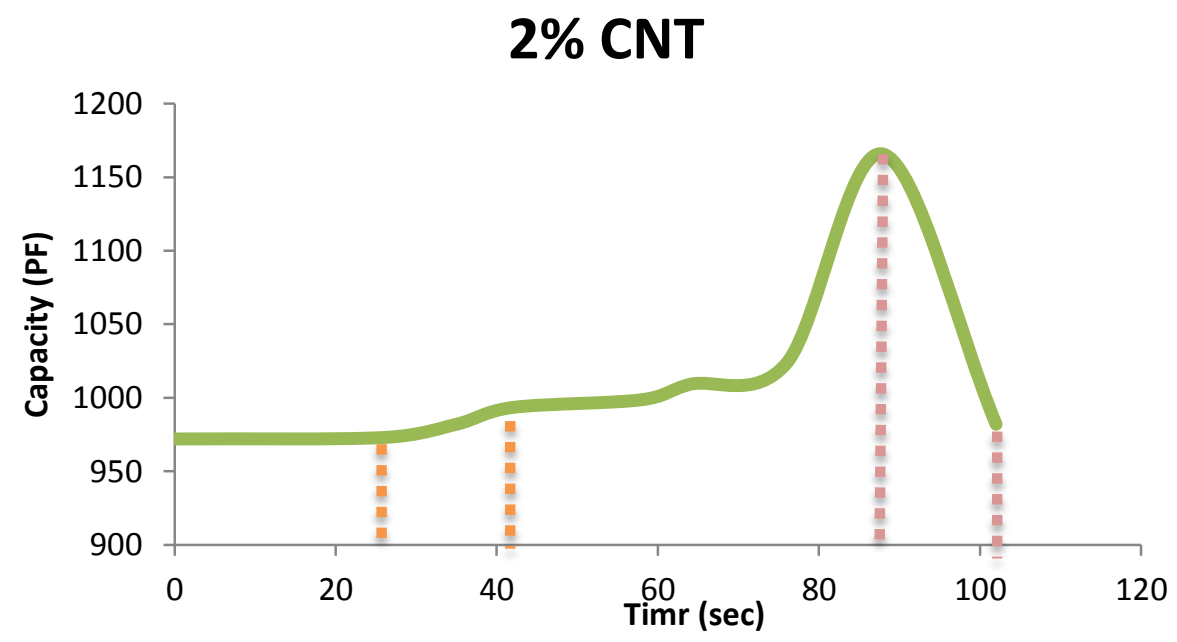

Fig.11: Response time and recovery time with $2 w t \%$ MWCNT. 


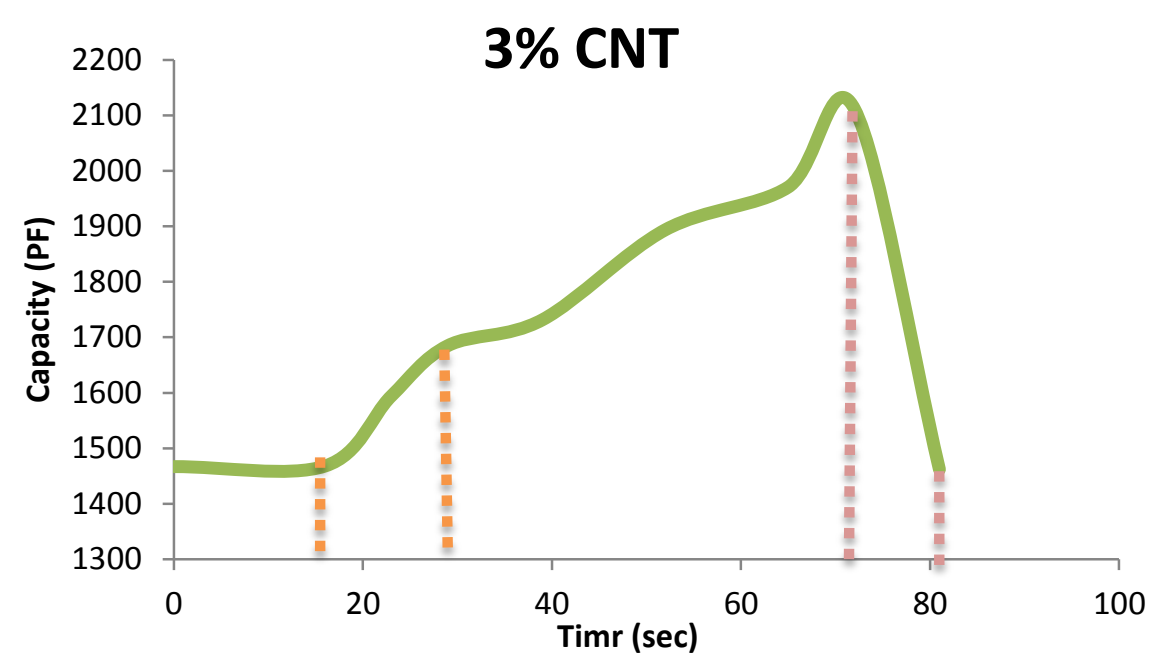

Fig.12: Response time and recovery time for humidity sensor with $3 w t \%$ MWCNT.

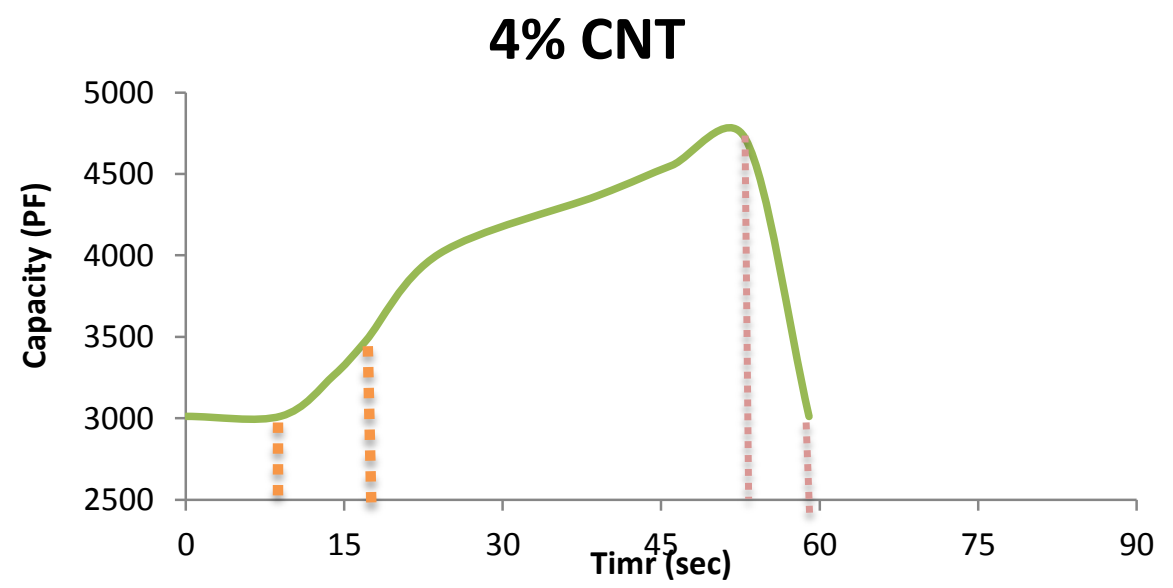

Fig.13: Response time and recovery time for humidity sensor with 4wt\% MWCNT.

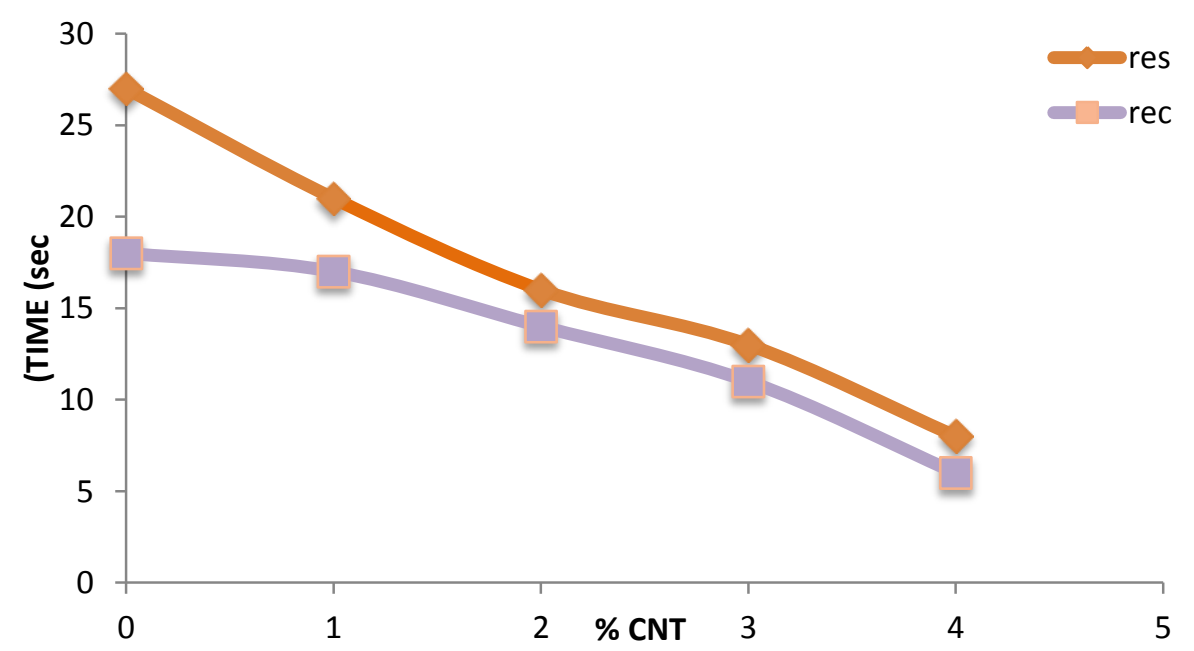

Fig. 14: Comparisons between response time and recovery time for humidity sensors as a function of MWCNT concentration. 
Table 1: The response time and the recovery time for PANI/MWCNT nanocomposite with different MWCNT concentration.

\begin{tabular}{|c|c|c|c|}
\hline $\begin{array}{c}\text { Concentratio } \\
\mathbf{n} \\
\text { Of MWCNT }\end{array}$ & $\begin{array}{c}\text { Sensitivity (S) } \\
\text { (PF / \% RH) }\end{array}$ & Res (sec) $\mathbf{T}$ & Rec (sec) $\mathbf{T}$ \\
\hline $0 \%$ & 0.55 & 27 & 18 \\
\hline $1 \%$ & 2.48 & 21 & 17 \\
\hline $2 \%$ & 3.2 & 16 & 14 \\
\hline $3 \%$ & 10.7 & 13 & 11 \\
\hline $4 \%$ & 28.3 & 8 & 6 \\
\hline
\end{tabular}

\section{Conclusions}

It can be concluded from this study that the change in MWCNTs concentration leads to a change in the energy gap as well as the initial capacity. The capacitance increases linearly with the relative humidity at MWCNTs concentration of $3 \%$ for thus the possibility of manufacturing humidity sensor with good specifications at this concentration.

\section{Reference}

[1] S.Iijima Helical, microtubules of graphitic carbon. Nature (London), (1991), 354: 56

[2] P. M. Ajayan, Chemical Reviews 99, 7 (1999) 1787-1799.

[3] M. S. Wang, L-M. Peng, J. Y. Wang, Q. Chen, The Journal of Physical Chemistry, B 109, 1 (2005) 110-113.

[4] Fan Shoushan, Michael G. Chapline, Nathan R. Franklin, Thomas W. Tombler, Alan M. Cassell, Hongjie Dai. Science 283, 5401 (1999) 512514.

[5] W. Bauhofer, J. Z. Kovacs, Compos and Sct. Technol., 69 (2009) 1486.

[6] E. A. Lysenkov, Y. V. Yakovlves, V. V. Klepko, UKR. Phys. J., 58 (2013) 378.

[7] S. Palaniappan, A. John, Prog. Polym. Sci., 33 (2008) 732-758. [8] S. Bhadra, D. Khastgir, N.K.
Singha, J.H. Lee, Prog. Polym. Sci., 34 (2009) 783-810.

[9] Karimov, Khasan S., Muhammad H. Sayyad, Mukhtar Ali, Muhammad N. Khan, Syed A. Moiz, Khurram B. Khan, Humera Farah, Zioda M. Karieva. Journal of Power Sources, 155, 2 (2006) 475-477.

[10] A. Elahi, M. H. Sayyad, Kh. S. Karimov, Kh. Zakaullah, M. Saleem. J. Optoelctronics \& Adv. Mat. Rapid. Comm, 1,7 (2007) 333-338.

[11] Chani, M. Tariq Saeed, Kh. S. Karimov, F. Ahmad Khalid, S. Abdul Moiz., Solid State Sciences, 18 (2013) 78-82.

[12] Chani, Muhammad Tariq Saeed, Kh. S. Karimov, Sher Bahadar Khan, Abdullah M. Asiri, M. Saleem, M. Mehran Bashir. Optoelectron Adv. Mater Rapid Commun, 7 (2013) 861865.

[13] M.V. Fuke, P. Kanitkar, M. Kulkarni, B.B. Kale, R.C. Aiyer, Talanta, 81 (2010) 320-326.

[14] N. Camaioni, G.C. Micelia, Y. Li, M.J. Yang, A. Zanelli, Sens. Actuators, B 134 (2008) 230-233.

[15] A.T. Ramaprasad, V. Rao, Sens. Actuators, B 148 (2010) 117-125. [16] R. Nohria, R.K. Khillan, Y. Su, R. Dikshit, Y. Lvov, K. Varahramyan, Sens. Actuators, B 114 (2006) 218222.

[17] A. Salehi, D.J Kalantari, A. Goshtasbi, Rapid Response of 
Au/Porous-GaAs Humidity Sensor at Room Temperature. In Proceedings of 2006 Conference on Optoelectronic and Microelectronic Materials and Devices, Perth, Australia, 6-8 December (2006) pp. 125-128.

[18] J. Fraden, "Handbook of Modern Sensors", Springer New York: New York, NY, (2010) pp.445-459. [19] HIH Series Humidity Sensors, Psychrometrics and Moisture, Reference and Application Data.
Honeywell: Morristown, NJ, USA, 2010, pp. 145-147.

[20] Barrau, Sophie, Philippe Demont, Alain Peigney, Christophe Laurent, and Colette Lacabanne. Macromolecules, 36, 14 (2003) 51875194.

[21] Hu, Guangjun, Chungui Zhao, Shimin Zhang, Mingshu Yang, Zhigang Wang. Polymer, 47, 1 (2006) 480-488. 